\title{
Crónica
}

\section{OPINIÓN DE LA ACADEMIA CHILENA DE MEDICINA SOBRE LA CERTIFICACIÓN DE ESPECIALISTAS}

Hace 6 años, las asociaciones médicas hicimos la declaración pública: "Una amenaza a la seriedad y prestigio de la medicina chilena", alertando al país, gobierno y parlamentarios, sobre las disposiciones de un proyecto de ley que establecía el reconocimiento como especialistas a médicos que no tenían esa condición, por no haber cumplido los requisitos exigidos por las universidades o una certificación de la Corporación Autónoma de Certificación de Especialidades Médicas (CONACEM). No obstante, la ley fue aprobada, quedando pendiente la reglamentación complementaria. El "Reglamento de Certificación de las Especialidades y Subespecialidades de los prestadores individuales de salud $y$ de las entidades que lo otorgan", fue tomado de razón en octubre del año 2008, estableciendo que, hasta el año 2015, aquellos médicos que sin ser especialistas hayan ejercido como tales bajo determinadas condiciones, se les otorgará un "certificado de competencias", lo que les habilitará para ser incorporados a la lista pública de especialistas médicos que, para conocimiento de la ciudadanía, deberá elaborar la Superintendencia de Salud.

Es conveniente destacar que los programas de formación de médicos especialistas, establecidos en el país hace más de 50 años por grandes maestros de la medicina, implican un entrenamiento de 3 años de duración con dedicación completa, turnos de residencia y las correspondientes evaluaciones. En las décadas posteriores, la Academia de Medicina, la Asociación de Facultades de Medicina, las Sociedades Médicas Científicas y el Colegio Médico, impulsaron sucesivos procesos institucionalizados de certificación de la calidad de los programas y de los centros de formación de los especialistas. La reconocida idoneidad de los especialistas chilenos se explica por el rigor con que son formados y el control de calidad de los respectivos programas. Esto es un motivo de orgullo para la profesión médica y una garantía para la población.

La Academia de Medicina, cuya misión es velar por el progreso y calidad de la medicina chilena, expresa su disconformidad con las disposiciones del reglamento aludido y reitera que el camino correcto para alcanzar la condición de especialista es cumplir con los programas de formación respectivos, o someterse a los exámenes de competencia que exige CONACEM.

La búsqueda de caminos alternativos impropios constituye un retroceso histórico para la medicina chilena, perturba la calidad de la atención médica y confunde a la opinión pública.

Santiago de Chile, noviembre de 2009 